\title{
Influences of communication problems on project performance in Nigeria
}

\author{
G. A. Yakubu ${ }^{1 *}$, O. E. Ogunsanmi ${ }^{1}$ and A. O. Yakubu ${ }^{2}$ \\ ${ }^{1}$ Department of Building, University of Lagos, Yaba, Akoka, Lagos, Nigeria. \\ ${ }^{2}$ Department of Estate, University of Lagos, Yaba, Akoka, Lagos, Nigeria.
}

Accepted 27 July, 2015

\begin{abstract}
Construction projects are known to perform poorly. Failure to achieve preconceived goals of construction project has been linked to ineffective communication among project team members. The aim of the study reported here is to assess communication problems in construction projects from the perspective of construction contractors. A large quantitative approach was adopted. This entailed the use of questionnaires to collect information on the perception of respondent on the study's objectives. The findings of the study suggest that a positive relationship exist between non-effective communication and project performance. Based on the findings, it is suggested that the use of face-to-face communication will ensure that problems are resolved faster.
\end{abstract}

Keywords: Communication, mixed method, Nigeria, project performance.

*Corresponding author. E-mail: yakubu.ganiyu@yahoo.com.

\section{INTRODUCTION}

Communication problems in construction projects often arise as a result of Internal influence classified as "Direct influence" results from lack of share understanding or poor communication between and amongst project participants in the area of project specifics and contractual commonalities; or External influence classified as "Indirect influence" resulting from project requirements which the project participants and owner(s) do not have control over like statutory requirement, regulatory condition, external supervision of health and safety (H\&S), environmental condition (weather), media, government, currency, inflation, infrastructure, the people, culture, language. However, the external influence really do not cause major problem to construction unlike the internal influence.

Construction projects, which are known for non standardized reporting matrix are characterized by varying organisational structures with differing delivery methods which are unique in that they are designed and executed to meet individual owners needs. Therefore, for effective project delivery construction parties must interface efficiently and attain considerable share understanding of the project delivery types and its condition of contract.

A project delivery method is the method agreed by construction parties to execute construction project and disseminate information in the course of such construction phase towards shared understanding and commonalities. A project delivery method is again defined as "a system used by an agency or owner for organizing and financing designs, constructions, operations, and maintenance services for a structure or facility by entering into legal agreements with one or more parties (Wikipedia, 2015)". Thus, for effective communication and project delivery performance in-terms of time and cost, the construction project data must be such that have ease of comprehension, must be sent and get to the intended receiver timely (horizontal communication channel), must be relatively cheap like verbal (face to face for worksite), must perform its purpose (work done to specification), and must have feedback inform of qualitative work. However, the likely problem that is imminent between the construction parties from noneffectiveness of communication are misunderstanding or incomprehension which might lead fast to further break down of communication that will trigger conflict, 
arbitration, litigation, delay of project, and possibly project abandonment.

Ruuska (1996) says that communication must be planned for as a resource in projects similar to other resource like time, money, people and equipment. The influence of communication not planned for on construction project may result to project underperformance and subsequently makes the project in question to overruns in-terms of time, cost and quality. "The aspect of quality overruns which is uncommon to many is also a critical aspect that have the influence of time (inform of information delay or miss-interpretation of instruction/design/specification) and cost (inform of selection of materials, availability of materials, sourcing of quality materials, inflation) which requires the intervention of an experienced clients".

Research reveals that effective communication, consultation and information-sharing between the client, designer and constructor are vital to project success, ensuring best practice, and promoting construction safety are influence to project success (Sperling et al., 2008). Information sharing in construction project management entails communication via architectural drawings, detailing drawings, schedule program of work, bills of quantities, specification notes, procurement methods, tender documents, condition of contracts, memorandum of understanding, and $\mathrm{H} \& \mathrm{~S}$ guidelines through which the contract parties sends, receives, agrees on, and implements information and also sends information to the public at large through other information media like the dailies, association magazines, professional bodies journals, internet and intranet of their process and procedure.

Careful project communication interface planning and setting the right expectations with all the project stakeholders is extremely important. Thus, conventional interface communication methods include face-to-face meetings, telephone communication, regular interface meeting, and virtual design and construction (VDC) (Siao et al., n.d.). Effective communication supports the development of positive relationships with the stakeholder community and can also be utilized to influence attitudes and behaviours within the wider environment (McDonald and Hammer, n.d.). Poor communication between clients and contractors is one of the factors that affect working efficiency and is a reason for the relatively low productivity of the construction maintenance sector (Hua et al., 2005). Clients have a limited understanding of the design, procurement and construction processes, which results in, inter alia, poor briefings and revised requirements (Aiyetan, 2010). Aiyetan (2010) further opines that communication has an adverse effect on the smooth delivery of projects. However, a large number of associated problems influence project delivery time performance: clients limited understanding of the procurement and construction process; inadequate design; poor quality management during design and construction; poor ground conditions; poor constructability; poor motivation of workers; non-participatory management style and adverse physical, economical, and socio-political factors.

Communication in the Nigeria Construction industry cannot be conclusively said to be effective as there are quite a number of researches, opinion papers, and professional bodies' journals on this aspect of construction project management as cited in Aibinu and Jagboro (2002), Aiyetan (2010) and Oresegun (2009). However, from our usual logical attitude and nonchallancy behavioural culture a seasonal researcher and a building expert or professional can infer through the rule of thumb that the Nigerian construction industry do experience communication problems vis-à-vis project delivery problems as does their counterparts in the developing countries and the developed countries of the world.

However, despite the many studies and discussions in the academics and practical literature, there are few case studies to explore what the real facing problems and solutions for total breakdown of communication during the construction phase. A major criticism facing the Nigerian construction industry is the growing rate of lack of share understanding of project specifics as a result of communication problems. Hence the study is aimed at determining the influences of communication problems on construction project performance in Nigeria.

Thus, this identified gap necessitate this study to explore the influence of communication problems (during the construction phase) on selected projects in Lagos metropolis in the areas of: The factors influencing the communication problem; The influence of these factors on project delivery in-terms of time, cost, quality of project; The most common and efficient method of disseminating projects information's to worksite; The impact of stakeholder's contribution to construction management of projects.

\section{LITERATURE REVIEW}

\section{Concept of communication used in construction industry}

Communication is the key factor in the success of any organization. When it comes to effective communication, there are certain problems that every organization faces. Influences to communication problems include message overload (when a person receives too many messages at the same time), and message complexity (inability to interpret).

According to Wikipedia (2015), communication is thus a process by which meaning is assigned and conveyed in an attempt to create shared understanding. This process, which requires a vast repertoire of skills in interpersonal processing, listening, observing, speaking, questioning, analyzing, gestures, and evaluating, enables collaboration and cooperation. Communication requires a 
sender, a message, and an intended recipient, although the receiver need not be present or aware of the sender's intent to communicate at the time of communication; thus communication can occur across vast distances in time and space.

Communications Management is the systematic planning, implementation, monitoring, and revision of the organization and dissemination of new communication directives connected with an organization, network, or communication technology (Wikipedia, 2015).

Communication during projects can be of many different types such as oral (verbal), written (non-verbal). Oral communication is mainly utilized in face-to-face meetings or over the telephone as well as in group meetings and affords a lot more flexibility to the speaker, such as the ability to communicate not only with voice but body language, attitude and nuance. The subtle nuances that can be communicated during verbal communication are not present during written communication. Written communication, on the other hand, is usually more precise. It can be sent through correspondence such as drawings, figures, symbols, memos, letters or notices. It can also be sent via Email or the project management information system. The key to making written communication more effective is to first grab people's attention, and then give them a reason to want to read the rest of the communication. Generally the method of information dissemination in most organizations are in one form or the other similar to the following; E-mailing, Job order card, Routine work card, Face-to-face, Notice board, Telephoning, etcetera-etcetera.

Over the years, several studies concluded thus that the construction sector could benefit from improved communication. Although the studies highlight several aspects of communication in construction, no literature overview has been found on demand-supply communication in construction. Studies have always focused on intra-supplier communication between head and subcontractors (Sperling et al., 2008). In the cases where communication between demand side parties and supply side parties was studied, the focus was on just a few stakeholders instead of taking into account many parties of each side, as cited in Hoezen et al. (2006).

\section{Use of communication in construction projects}

During a project communication can occur in various directions depending on who is communicating. There is upward communication from field artisan/Supervisor to the project management and lateral or horizontal communication takes place with client organization and between project teams (Oresegun, 2009; Mehta, n.d.). Many factors can cause barriers to effective communication and likewise impact negatively on project delivery performance. The principal reason for this is that there has been changes in the attitude of workers to their employers and in the present site environment and there has been a move away from old concepts of unquestionable obedience, proper provision must be made for upward communication to avoid misconceptions of information otherwise a superior personnel like Architect, Project Manager, Engineer or Supervisor may generate a bad feeling and may also end up making decisions in a vacuum and such decision may not be accepted by the junior staffs and personnel like the labourers and gang men (Oresegun, 2009).

\section{Communication of contract award processes}

To enhance effective two-way communication flow and share understanding (irrespective of the procurement type) between the client, consultant, contractor, and supplier and even at contract tender sorting, selection and negotiation during contract procurement. Sufficient communication procedure, medium, and precise message form must be identified. The message should be such that is devoid of ambiguity and the channels should be as short as possible in order to minimise noise interference. This could be facilitated through face-to-face discussions, workshops, emails or tele/videoconferencing.

\section{E-mail versus face-to-face communications as an aid to effective communication}

Much could be learned about the receptiveness to change if one could find out if the attitudes and behaviours towards adopting IT among indigenous contractors and international contractors are the same. Reasons for adopting IT technology that are specific to the construction industry have been discussed by Mitropoulos and Tatum (2002) as cited in Trefor et al. (2007). They stressed additional factors such as the need to solve construction process problems quickly, the desire to seek competitive advantage over competing firms (indigenous and international firms competitions) irrespective of size (medium to large firms) and external requirements from owner organizations to implement new technologies (Trefor et al., 2007).

Amami and Beghini (2000) stated that although email is regarded by Weinstock (2006) as a useful communication technology, the ability to convey the meaning via body language, cadence and tone are lost, with the potential for content to be misconstrued. For these reasons, Cheng et al. (2001) and Hua et al. (2005) prefer face-toface communication both at project award phase and construction phase. Again, in multicultural project teams the loss of face-to-face communication can lead to misunderstanding and the loss of non-verbal signals such as eye contact and body language (Ochieng and Price, 2010). Cheng et al. (2000) as cited in Meng (2012) 
opines that in addition to open exchange of information, effective communication facilitates the exchange of ideas and visions, which can result in fewer misunderstanding and stimulate mutual trust. Thus, Chen and Chen (2007) say by comparison, two-way communication is more effective and should be encouraged, which can maximize understanding and minimize misinterpretation. There is also the need to build trust amongst construction parties to further ensure cooperative relationship and forestall project free conflicts.

This study has categorized E-mail and face-to-face communication into 6 performance indicators for the purpose of comparison: Time savings, cost effectiveness, productivity, stock of data, client's satisfaction, and contractor's satisfaction.

\section{Factors influencing human communication problems on construction projects}

Sosa et al. (2002) holds valid in one of their hypotheses that; "Communication frequency is higher between individuals who share an organizational bond, independently of the communication media used". Yet on daily basis communication problems in construction are still inevitable (Emmerson, 1962; Higgin and Jessop, 1965; Latham, 1994; DETR 1998) as cited in Hoezen et al. (2006). Due to its specific characteristics, the industry forms a complex communication environment through the different organizational structures (example matrix organization, line organization, etc) and span of control it is composed of. Construction is a fragmented and dynamic sector with a project based nature. This holds that many stakeholders operate in frequently changing sets of relationships which are contractually motivated. Thus such culture shows a reality of interference, conflicts, lack of mutual respect and trusts (Dainty et al., 2006). The following are associated with face-to-face and constitute problems to human communication in construction industry world over; Physical barrier problems, Defective organizational structure problems, Attitudinal problems, Ambiguity of words/phrases, Individual linguistic ability, Physiological problems, Simplistic information presentation, communication and feedback and work pressure. However, according to Sosa et al. (2002) three major geographical barriers to communication process were identified, namely; physical distance, overlapping working time and cultural/language differences.

\section{Communication problems results from barriers to effective human communication}

Physical barriers: Physical barriers are environment based problems that do occur on site, which may also exist as result of distance location, poor or outdated equipment, failure of management to introduce new technology, staff shortages, background noise, poor light, morale, concentration.

Defective organizational structure: System design faults often occur with the structures or system in place in an organization. This ranges from unclear organizational structures (who to report to), inefficient information system, lack of supervision, lack of training, lack of clarity in roles and responsibility.

Attitudinal barriers: Attitudinal barriers come about as a result of problems with staff behaviour in an organization. Examples are poor management, lack of consultation, conflicts, refusing to communicate, lack of motivation, dissatisfaction, insufficient, training, resistance to change.

Ambiguity of words/phrases: When a communicator uses words that sound the same but which conveys different meaning. Examples are too high a grammar, colloquial words.

Individual linguistic ability: The use of difficult or inappropriate words in communication can prevent people from understanding the message; hence, the use of native language.

Physiological barriers: May result from individuals' personal discomfort, caused for example by ill-health, poor eye sight or hearing difficulties.

Presentation of information: The act of presenter to simplify his/her vocabulary when considering the audience that desires the lecture/speech.

Communication and feedback: These affects communication in construction in positive or negative manners. They occur in the form; regular site meeting, workers are allowed to report design errors and unsafe construction method and working condition, management plans are discussed openly, feedbacks are useful for management re-plan for corrective measures.

Work pressure: The firm is only concerned with getting the job done as quickly as possible; workers are also compelled to work shifts or overtime.

\section{Stakeholders' contributions to communication on construction projects}

The importance of communication in the success of a project is immense. Careful communication planning and setting the right expectations with all the project stakeholders is extremely important. Face to face initial communication within the project team to establish the 
team dynamics and learning the customer's expectations are the keys to success when starting a project. Throughout my years as a project manager, my belief that the success of a project is a matter of effective communication has been continuously reinforced.

As listed by Kerzner as cited in Mehta (n.d.), typical literary definitions of effective communications include:

(i) An exchange of information

(ii) An act or instance of transmitting information

(iii) A verbal or written message

(iv) A technique for expressing ideas effectively

(v) A process by which meanings are exchanged between individuals through a common system of symbols.

Effective communication involves both sending and receiving the message that is accomplished finally with a feedback (two-way communication). With this in mind, a good definition of project communication management can be "Project Communications Management includes the process required to ensure timely and appropriate generation, collection, dissemination, storage, and ultimate disposition of project information" (Project management institute standards committee, 1996:103) as cited in Mehta (n.d.).

\section{RESEARCH METHOD}

The research centred on the objectives of the study by collecting primary data through the use of structured questionnaires at visitation to selected medium to large size construction companies ranging from multinational to indigenous contractors in Nigeria. The descriptive research process (using mean, standard deviation and ranking) and inferential statistic (using One way ANOVA and One sample T-test) was adopted which provided answers to unanswered questions about the subject of the study and to make generalization of its findings about the population. A large quantitative survey approach was adopted on the population of study which is made up of project managers, contractors, consultants, clients, government, supervisors and field workers. The total 100 construction companies that are registered corporate organisation with Federation of Construction Industry $(\mathrm{FOCl})$ out of the present 200 eligible contracting and consulting firms was considered provided they granted access to their head or branch offices and as well their ongoing construction worksite. Note; there must be an ongoing worksite per Construction Company to be able to observe the medium of communication style and basic communication problems through mixed design survey. Thus, the response rate eventuates to $30 \%$. Though, there were non-valid questionnaires that could not be representative of the population of the survey as a result of missing vital data and firm categories. The Sampling technique was Non-probability sampling techniques that focus on the population primary data essentially. For this study "Medium firm staff strength: $50>P<100$; Large firm staff strength: $P>100$ ". This study has categorized E-mail and Face-to-face communication into 6 performance indicators for the purpose of comparison: Time savings, cost effectiveness, productivity, stock of data, client's satisfaction, and contractor's satisfaction. Whilst 9 other broad categories were identified for factors influencing communication problems namely: Attitudinal barriers, Phrase barriers, Presentation barriers, Physical barriers, System barriers, Ability barriers, and Physiological barriers, Communication and feedback, and work pressure.

\section{RESULTS}

\section{Factors influencing communication problems}

Factors influencing communication as identified in literatures are 9 broad categories namely: Attitudinal barriers, Phrase barriers, Presentation barriers, Physical barriers, System barriers, Ability barriers, and Physiological barriers, Communication and feedback, and work pressure. Table 1 gave attitudinal barriers/problem as the most influencing factors considering the mean of all its sub-factors. Thus, this correlates to Awakul and Ogunlana (2002) findings which validate the fact that construction parties develop negative attitudes that lead to conflict when their views are not given adequate attention. He further reiterates that effective partnership is the solution to effective communication on development projects. Physical problem returned as the second severe factor with 27.73 mean and Defective structure returned with 16.70 as the third severe problem in the category of nine major causative factors. Though, the least influencing factor of this study is work pressure.

\section{Effects of the problems on communication}

Table 2 shows the following: motivation (3.80), dissatisfaction of workers (3.76), refusal to communicate (3.73), training (3.70) and poor management (3.60) as the $1^{\text {st }}, 2^{\text {nd }}, 3^{\text {rd }} 4^{\text {th }}$, and $5^{\text {th }}$ respectively most pressing effects on the communication problems in table one above. However, the less severe effects among a list of 36 factors are: inefficient information impact $(3.00$ moderate impact with respect to 5 point likert scale), poor light impact (2.93), environmental impact (2.90), overtime impact (2.80) and background noise impact (2.80) which returned on rank $33,34,35,36$ and 36 , respectively.

\section{Effectiveness of email and face-face communication on construction projects}

Email communication from all indication and justification 
Table 1. Communication influences factors.

\begin{tabular}{lcccc}
\hline Communication problem factors & N & Sum & Mean & Rank \\
\hline Attitudinal problem & 30 & 848 & 28.24 & 1 \\
Physical problem & 30 & 832 & 27.73 & 2 \\
Defective organization problem & 30 & 501 & 16.70 & 3 \\
Communication and feedback problem & 30 & 419 & 13.96 & 4 \\
Physiological problem & 30 & 303 & 10.10 & 5 \\
Linguistic ability problem & 30 & 209 & 6.97 & 6 \\
Ambiguity/phrase problem & 30 & 199 & 6.63 & 7 \\
Presentation problem & 30 & 196 & 6.53 & 8 \\
Work pressure & 30 & 185 & 6.17 & 9 \\
\hline
\end{tabular}

Source: Field survey (2015).

Table 2. Communication impact factors.

\begin{tabular}{|c|c|c|c|c|}
\hline Communication impact factors & $\mathbf{N}$ & Mean & Std. deviation & Rank \\
\hline Motivation impact & 30 & 3.80 & .887 & 1 \\
\hline Dissatisfaction of workers impact & 29 & 3.76 & 1.057 & 2 \\
\hline Refusal to communicate impact & 30 & 3.73 & 1.143 & 3 \\
\hline Training impact & 30 & 3.70 & .952 & 4 \\
\hline Poor management impact & 30 & 3.60 & 1.248 & 5 \\
\hline Open discussion impact & 30 & 3.60 & 1.037 & 5 \\
\hline Insufficient training impact & 30 & 3.60 & .855 & 5 \\
\hline Supervision impact & 30 & 3.57 & 1.073 & 8 \\
\hline Re-plan impact & 30 & 3.57 & 1.478 & 8 \\
\hline Inappropriate words impact & 30 & 3.50 & 1.167 & 10 \\
\hline Grammar impact & 30 & 3.50 & 1.225 & 10 \\
\hline Hearing impact & 29 & 3.48 & .911 & 12 \\
\hline Poorly explained message impact & 30 & 3.47 & 1.332 & 13 \\
\hline III-health impact & 30 & 3.47 & 1.137 & 13 \\
\hline Design errors impact & 30 & 3.43 & 1.194 & 15 \\
\hline Poor outdated equipment impact & 29 & 3.41 & 1.150 & 16 \\
\hline New technology impact & 30 & 3.40 & 1.429 & 17 \\
\hline Resistance to change impact & 30 & 3.40 & .894 & 17 \\
\hline Conflict impact & 30 & 3.37 & 1.033 & 19 \\
\hline Quick job impact & 30 & 3.37 & 1.426 & 19 \\
\hline Regular site meeting impact & 30 & 3.37 & 1.351 & 19 \\
\hline Audience capturing impact & 30 & 3.33 & 1.184 & 22 \\
\hline Poor eye sight Impact & 30 & 3.27 & 1.048 & 23 \\
\hline Morale impact & 30 & 3.27 & 1.048 & 24 \\
\hline Role and responsibility impact & 30 & 3.23 & .935 & 25 \\
\hline Vocabulary simplification impact & 30 & 3.20 & 1.126 & 26 \\
\hline Organizational structure impact & 30 & 3.20 & 1.448 & 26 \\
\hline Location impact & 29 & 3.14 & 1.156 & 28 \\
\hline Colloquial words impact & 30 & 3.13 & 1.224 & 29 \\
\hline Consultation impact & 30 & 3.13 & 1.042 & 29 \\
\hline Concentration impact & 30 & 3.07 & 1.311 & 31 \\
\hline Staff shortage impact & 30 & 3.03 & 1.159 & 32 \\
\hline Inefficient information impact & 30 & 3.00 & .947 & 33 \\
\hline Poor light impact & 30 & 2.93 & 1.311 & 34 \\
\hline Environmental impact & 30 & 2.90 & 1.185 & 35 \\
\hline Overtime impact & 30 & 2.80 & 1.297 & 36 \\
\hline Background noise impact & 30 & 2.80 & 1.375 & 36 \\
\hline Valid N (listwise) & 27 & & & \\
\hline
\end{tabular}

Source: Field survey (2015). 
Table 3. Effectiveness of email communication.

\begin{tabular}{lcccc}
\hline Email effectiveness on communication & N & Mean & Std. deviation & Rank \\
\hline Time Saving & 30 & 3.67 & 1.493 & 1 \\
Productivity & 30 & 3.63 & 1.129 & 2 \\
Client's Satisfaction & 30 & 3.53 & 1.332 & 3 \\
Cost Effectiveness & 30 & 3.50 & 1.196 & 4 \\
Stock of Data Records & 30 & 3.43 & 1.406 & 5 \\
Contractor's Satisfaction & 30 & 3.43 & 1.135 & 6 \\
Valid N (listwise) & 30 & & & \\
\hline
\end{tabular}

Source: Field survey (2015).

Table 4. Effectiveness of face-face communication.

\begin{tabular}{lcccc}
\hline Face-face effectiveness on communication & N & Mean & Std. Deviation & Rank \\
\hline Client's satisfaction & 30 & 3.67 & 1.493 & 1 \\
Contractor's satisfaction & 30 & 3.20 & 1.690 & 2 \\
Productivity & 30 & 3.07 & 1.617 & 3 \\
Cost effectiveness & 30 & 2.90 & 1.583 & 4 \\
Time saving & 30 & 2.77 & 1.569 & 5 \\
Stock of data records & 30 & 2.63 & 1.564 & 6 \\
Valid N (listwise) & 30 & & & \\
\hline
\end{tabular}

Source: Field survey (2015).

is no doubt meant for quick, readable and well explanatory messages that must be detailed in its content and can serve as an evidence for contractual intentions. Often for site productivity and efficiency, the head offices communicate with their branch offices at worksites by emailing necessary contract parties instructions as regards the project proceedings and verification might also be carried out by clients and its consultants using pictures of site layout, topography, level of construction activities required and executed, constructions reworks, supplies, prospective suppliers and subcontractors quotations etcetera. Below is the feedback of the survey on effectiveness of email communication on project performance as time saving, productivity and client satisfaction returned as $1^{\text {st }}, 2^{\text {nd }}$ and $3^{\text {rd }}$ respectively most effective factors with respect to 5 point likert scale description $(5=$ very severe, $4=$ severe, $3=$ moderate severity, 2 = less severe, 1 = not severe). (Table 3 )

Face to face communication as is the practice of onsite communication means which is often meant for immediate decoding and share understanding between the sender and receiver of the message. There are psychological reactions associated with face to face communication which passes the seriousness and importance of the immediate instructions. Such seriousness comes as body language, cadence, subtle, grimace, grin, anger, acceptance, confidence, etc; where these can be linked to self-efficacy, workload characteristics and role clarity. Thus, the following factors returned as $1^{\text {st }}, 2^{\text {nd }}$ and $3^{\text {rd }}$ most effective factors; client's satisfaction, contractors' satisfaction and productivity respectively. This result is valid as clients do always prefer regular site meetings to convey instructions as related to change order, design explanation by the Architect and the target time and cost under which the project must be delivered. Again, the convergence variables between effectiveness of email communication and face-face communication are clients' satisfaction and productivity (Table 4).

\section{Contribution of stakeholders to communication management on construction projects}

Table 5 is the result of the field survey on the level of contribution of stakeholders to communication on construction projects which gave Project managers (4.30) as $1^{\text {st }}$. Consultants (4.23) as $2^{\text {nd }}$ and Contractors (3.87) as $3^{\text {rd }}$. The least contribution came from the masses which form the bulk of artisan, labourers and other field workers that has one dealing or the other on site activities.

\section{DISCUSSION}

Both the null and alternative hypothesis postulated for findings solution to the study objective are as follows: 
Table 5. Contribution of stakeholders to communication.

\begin{tabular}{lcccc}
\hline Stakeholders & N & Mean & Std. deviation & Rank \\
\hline Project managers & 30 & 4.30 & .794 & 1 \\
Consultants & 30 & 4.23 & .898 & 2 \\
Contractors & 30 & 3.87 & 1.196 & 3 \\
Clients & 30 & 3.73 & 1.202 & 4 \\
Government & 30 & 3.63 & 1.066 & 5 \\
Users & 30 & 3.17 & 1.147 & 6 \\
Valid N (listwise) & 30 & & & \\
\hline
\end{tabular}

Source: Field survey (2015).

Table 6. One sample T-test for significant impact of communication problems.

\begin{tabular}{lcccccc}
\hline \multirow{2}{*}{ Parameter } & $\mathbf{t}$ & df & Sig. (2-tailed) & \multirow{2}{*}{ Mean difference } & \multicolumn{2}{c}{ 95\% Confidence Interval of the Difference } \\
\cline { 6 - 7 } & & & & & Lower & Upper \\
\hline Physical barriers & 11.587 & 29 & .000 & 2.800 & 2.31 & 3.29 \\
System barriers & 11.653 & 29 & .000 & 2.733 & 2.25 & 3.21 \\
Attitudinal barriers & 15.908 & 29 & .000 & 3.367 & 2.93 & 3.80 \\
Phrase barriers & 13.980 & 29 & .000 & 3.067 & 2.62 & 3.52 \\
Ability barriers & 12.173 & 29 & .000 & 2.733 & 2.27 & 3.19 \\
Physiological barriers & 9.898 & 29 & .000 & 2.500 & 1.98 & 3.02 \\
Presentation barriers & 13.408 & 29 & .000 & 2.900 & 2.46 & 3.34 \\
\hline
\end{tabular}

Test Value $=0$. Source: Field survey (2015).

Table 7. Crosca-wallis test [One way ANOVA on ordinal scale (A non-parametric test)].

\begin{tabular}{lccccc}
\hline Comparisons of total scores & Sum of squares & df & Mean square & F & Sig. \\
\hline Between groups & 13509.078 & 8 & 1688.635 & 146.584 & .000 \\
Within groups & 1969.900 & 171 & 11.520 & & \\
Total & 15478.978 & 179 & & & \\
\hline
\end{tabular}

Source: Field survey (2015).

\section{Hypothesis one}

$\mathrm{H}_{1}$ : Physical barriers, attitudinal barriers, ambiguity of words, individual linguistic ability, physiological barriers and presentation of information are not impact of communication problem on project delivery.

By using one sample t-test, the study examines problems that are impacts of communication problems. To carry out this, the score for the impacts is computed and tested against test value (a benchmark score), set at 0.00 and at 0.05 level of significance. The outcome is given in Table 6 .

From Table 6, at 5\% level and 29 degree of freedom; $t_{\text {tab }}<t_{\text {cal }}$, also $P<0.05$, implying that physical barriers, attitudinal barriers, ambiguity of words, individual linguistic ability, physiological barriers and presentation of information are not impact of communication problem on project delivery. Thus, accept the null hypothesis.

\section{Hypothesis two}

$\mathrm{H}_{2}$ : There is no significant difference between the impacts of communication problems on communication.

Table 7 is a representative of impact of communication problems on communication which is analysed using one way ANOVA.

The assumption is significance value $<0.05$ then the hypothesis is accepted. Therefore, there is no significance difference between the impacts of communication problems on communication. We thus accept the null hypothesis. The meaning of this is that we have convergence and correlation between hypotheses one and two in that individually; physical barriers [distance location, poor or outdated equipment, failure of management to introduce new technology, staff shortages, background noise, poor light, morale, 
T able 8. Factor grouping using Varimax rotation with Kaiser Normalization.

\begin{tabular}{|c|c|c|c|c|c|c|c|c|c|c|c|c|c|}
\hline & Parameter & 1 & 2 & 3 & 4 & 5 & 6 & 7 & 8 & 9 & 10 & 11 & 12 \\
\hline 1 & Client's Satisfaction e-mail & 1.000 & $.795^{\star *}$ & $.678^{* *}$ & $.553^{* *}$ & $.756^{\star *}$ & $.683^{* *}$ & $.743^{* *}$ & & & & & \\
\hline 2 & Contractor's Satisfaction e-mail & $.795^{\star \star}$ & 1.000 & $.480^{\star *}$ & $.734^{\star *}$ & $.493^{* *}$ & $.591^{\star *}$ & $.612^{* *}$ & & & & & \\
\hline 3 & cost effectiveness e-mail & $.678^{\star *}$ & $.480^{\star *}$ & 1.000 & $.570^{\star *}$ & $.865^{\star *}$ & $.761^{\star *}$ & $.684^{\star *}$ & & & & & \\
\hline 4 & Productivity e-mail & $.553^{* *}$ & $.734^{\star *}$ & $.570^{* *}$ & 1.000 & $.564^{* *}$ & $.537^{* *}$ & & & & & & \\
\hline 5 & Time Saving e-mail & $.756^{\star \star}$ & $.493^{* *}$ & $.865^{\star *}$ & $.564^{\star *}$ & 1.000 & $.648^{\star *}$ & $.660^{* *}$ & & & & & \\
\hline 6 & Stock of Data Records e-mail & $.683^{* *}$ & $.591^{\star *}$ & $.761^{\star *}$ & $.537^{\star *}$ & $.648^{* *}$ & 1.000 & $.763^{* *}$ & & & & & \\
\hline 7 & Client's Satisfaction & $.743^{* *}$ & $.612^{* *}$ & $.684^{* *}$ & & $.660^{* *}$ & $.763^{* *}$ & 1.000 & & & & & \\
\hline 8 & Contractor's Satisfaction & & & & & & & $.661^{* *}$ & 1.000 & $.578^{* *}$ & $.641^{* *}$ & $.658^{* *}$ & $.568^{* *}$ \\
\hline 9 & Cost Effectiveness & & & & & & & & $.578^{* *}$ & 1.000 & $.810^{* *}$ & $.752^{\star *}$ & $.732^{\star *}$ \\
\hline 10 & Productivity & & & & & & & & $.641^{* *}$ & $.810^{* *}$ & 1.000 & $.743^{* *}$ & $.745^{* *}$ \\
\hline 11 & Time Saving & & & & & & & & $.658^{* *}$ & $.752^{\star \star}$ & $.743^{\star *}$ & 1.000 & $.789 * *$ \\
\hline 12 & Stock of Data Records & & & & & & & & $.568^{* *}$ & $.732^{\star *}$ & $.745^{\star *}$ & $.789 * *$ & 1.000 \\
\hline
\end{tabular}

Field survey (2015).

concentration] or system barriers [unclear organizational structures (who to report to) inefficient information system, lack of supervision, lack of training, lack of clarity in roles and responsibility] or attitudinal barriers [poor management, lack of consultation, conflicts, refusing to communicate, lack of motivation, dissatisfaction, insufficient, training, resistance to change] are separately devastating and destructive to Project delivery and at the other hand communication in/on and within the project phases and interfaces.

\section{Hypothesis three}

$\mathrm{H}_{3}$ : There is no significant relationship between the impact of e-mail communication and project delivery.

Table 8 presents the Varimax rotation with Kaiser Normalization which has 1.000 value at the major diagonal and the residual values left on either side of this diagonal are such that has. These values are the significant values which imply strong relationship with the other on vertical axis as its corresponding on the horizontal axis. Thus the residual are selected on the assumption of values $>0.05$ significance. Therefore, the row 1 which is clients satisfaction of e-mail is significant and has very strong relationship with client satisfaction, contractor satisfaction, cost effectiveness, productivity, time savings and stock of data on $1^{\text {st }}$, $2^{\text {nd }}, 3^{\text {rd }}, 4^{\text {th }}, 5^{\text {th }}$ and $6^{\text {th }}$ column with the values $1.000,0.795,0.678,0.553,0.756$ and 0.683 , respectively.

\section{CONCLUSION AND RECOMMENDATIONS}

\section{Conclusion}

The converging points of observation from this survey carried out are thus concluded as follows:
There is no significance difference between the impacts of communication problems on communication as this is evident in hypothesis two (Table 7) where physical barriers, attitudinal barriers, ambiguity of words, individual linguistic ability, physiological barriers and presentation of information have separate resultant effect and impact of communication problem on project performance. E-mail has been effective as project management means of conveying contracts messages on the practiced delivery methods as itemised above inform of time savings, productivity and clients' satisfaction. Thus, e-mail is significant and has very strong relationship with client satisfaction, contractor satisfaction, cost effectiveness, productivity, time savings and stock of data (Table 8) which implies that there is effectiveness of e-mail communication. The higher the effect impacted on project delivery performance the better overall satisfaction which prevents conflicts, litigations, arbitration and total abandonment of projects. 
Client satisfaction and productivity are project variables with convergence for email and face-face communication effectiveness in construction projects in developing country like Nigeria. Others are not convergence variables but are highly significant to email and face-face communications and are time savings and contractor satisfaction respectively.

\section{Recommendations}

1. The effects of communication problems on communication inform of attitudinal problems, physical problems, defective organization problems, communication and feedback problems; can be improved correspondingly by $1^{\text {st }}$ through Management commitment to effective communication learning and training scheme of the workers to ensure that the workers are in good condition of health (listening ability, eye sight correctness and balanced psychological state of mind).

2. Avoid the attitudinal barriers to communication to set-in at early incidences of misunderstanding which often come inform of "refusal to communicate".

3. E-mail and face-to-face communication must be adopted to quickly resolve likely delay, poor quality work and misunderstanding that might want to affect the performance of project delivery.

4. The bulk of people that are recipient of the end product of communication on construction worksites are the Artisan and other field workers which form the bulk of users of all communication inputs and instructions. Therefore these sets of people must be carter for and Project Managers must possess good communication skill to effectively execute the projects through them.

\section{Contribution to knowledge}

Project communication issues are really talked about as a result of lack of sensitization, orientation, symposia and workshops held over it. The society which supposed to be fully endowed with language culture, ethnic culture and religious culture communication, such that the language used as medium is quite flexible but the ultimate goal is shared understanding. Otherwise, communication problem drastically triggered contractual problems like: litigation, arbitration, damages, conflicts, unwillingness to communicate are the order of the day and this therefore call for this study to bring about awareness to curb the social implication in the society and also at construction workplaces world over. The sensitization of project communication importance write up on construction industry in Nigeria would assist the stakeholders in the construction industry to avoid unwillingness to communicate that often trigger other communication problems; Again, help make it compulsory that defining the means and mode of communication on differing projects are stated and agreed upon by contractual parties at procurement phases. The importance of these will further improve on our contractual relationship skill, payment and award skill, planning, scheduling of project delivery within budgeted time and cost, productivity of construction materials and machine, health and safety communication and records, communication best practices becomes a dynamic culture system for Nigeria construction workers and industry. Records of investment growth, positive GDP, exportation of the resources in the Nigeria construction industry in-terms of skilled labour, real estate investment, and property investment, project management etcetera becomes the order of the day in the construction industry in Nigeria.

\section{ACKNOWLEDGEMENT}

This research work has been solely a personal effort of an ongoing $\mathrm{PhD}$ programme in Construction Management in the University of Lagos, Akoka. This work has been well gone through by the supervisor and Course lead "Advance Building Construction Management - BLD950"; Prof Ogunsanmi O. E., of the Department of Building, University of Lagos, Akoka, Yaba, Nigeria. There is no financial support whatsoever from any source on this research course work.

\section{REFERENCES}

Aibinu AA, Jagboro GO, 2002. The effects of construction delays on project delivery in Nigerian construction industry. Int J Project Manag, 20:593-599.

Aiyetan $A O, 2010$. Influences on Construction Project Delivery Time. (Doctoral dissertation, Nelson Mandela Metropolitan University, 2010). Retrieve in April 30, 2012 from http://osun.org.

Amami M, Beghini G, 2000. Project management and communication of product development through electronic document management. Project Manag J, 31(2):6-19.

Awakul P, Ogunlana SO, 2002. The effect of attitudinal differences on interface conflicts in large scale construction projects: A case study. Construct Manag Econ, 20:365-377.

Chen WT, Chen TT, 2007. Critical success factors for construction partnering in Taiwan. Int J Project Manag, 25(5):475-484.

Cheng E, Li H, Love P, Irani Z, 2001. Network communication in the construction industry. Corporate Commun, 6(2):61-71.

Cheng EWL, Li H, Love PED, 2000. Establishment of critical success factors for construction partnering. J Manag Eng, 16(2):84-92.

Dainty A, Moore D, Murray M, 2006. Communication in construction; theory and practice. Taylor and Francis.

DETR, 1998. The Report of the Construction Industry Task Force: Rethinking Construction (The Egan Report), HMSO.

Emmerson H, 1962. Survey of Problems before the Construction Industries: A Report prepared for the Minister of Works, HMSO.

Higgin G, Jessop N, 1965. Communication in the Building Industry. The Report of a Pilot Study for the award of Master of Science in Building Technology.

Hoezen M, Reymen I, Dewulf G, 2006. The problem of communication in construction. Retrieved June 2012 from www.scholargoogle.com.

Hua G, Sher W, Pheng L, 2005. Factors affecting effective communication between building clients and maintenance contractors. Corporate Commun, 10(3):240-252. 
Latham M, 1994. Constructing the Team - Joint Review of Procurement and Contractual.

McDonald S, Hammer A, n.d. "Stakeholders", Section 3. Information and Communication. Retrieve 30th April, 2012 from http://google.com.

Mehta A, n.d. Communication in Project Management. Retrieve $\begin{array}{llll}\text { February } & 19, & 2012 & \text { from }\end{array}$ http://en.wikipedia.org/wiki/Communication_management.

Meng X, 2012. The effect of relationship management on project performance in construction. Int J Project Manag, 30:188-198.

Mitropoulos $\mathrm{P}$, Tatum CB, 2002. Forces driving adoption of new information technologies. J Constr Eng Manag, 126(5):340-348.

Ochieng EG, Price ADF, 2010. Managing cross-cultural communication in multicultural construction project teams: The case of Kenya and the UK. Int J Project Manag, 28:449-460.

Oresegun $O, 2009$. Effective communication as an aid to construction project delivery. Retrieved from Scibd on www.google.com.ng in April, 2012.

Ruuska K, 1996. Project Communication. Project Management Consultant Espoo, Finland. Proceedings "IPMA 96" World Congress on Project Management - Paris, France. IC8, P 67 - 76.

Siao F, Shu Y, Lin Y, n.d. Interface Management Practices in Taiwan Construction Project. Department of Civil Engineering, National Taipei University of Technology, Taipei, Taiwan, (s1340333@ntut.org.tw).

Sosa ME, Eppinger SD, Pich M, McKendrick DG, Stout SK, 2002. Factors that influence technical communication in distributed product development: An empirical study in telecommunications industry. IEEE Trans Eng Manag, 49(1):45-58.

Sperling LM, Charles MB, Ryan RA, Brown KA, 2008. Driving Safety: Enhancing Communication between Clients, Constructors and Designers. In Proceedings of Third International Conference of the Cooperative Research Centre (CRC) for Construction Innovation Clients Driving Innovation: Benefiting from Innovation, 12-14 March 2008, Gold Coast, Australia. Retrieve Jan 5, 2013 from eprints.qut.edu.au.

Trefor W, Leonhard B, Huanqing L, 2007. Adoption patterns of advanced information technologies in the construction industries of the United States and Korea. J Construction Eng Manag, 133(10): 780-790.

Weinstock J, 2006. You've got mail-again (and again). T.H.E. Journal, 33(11): 4-8.

Wikipedia, 2015. Effective Communication and Communication channel. Retrieve February 19, 2015 from http://en.wikipedia.org/wiki/Communication_management.
Citation: Yakubu GA, Ogunsanmi OE, Yakubu AO, 2015. Influences of communication problems on project performance in Nigeria. Afr J Eng Res, 7(3): 74-84. 